Pecvnia, 8 (2009), pp. 97-120

\title{
Ofrendas para la edificación de la Catedral de Segovia
}

Recibido: Noviembre 2008

Aceptado: Septiembre 2009

\author{
Miguel Ángel Cillanueva de Santos \\ mcillanueva@educa.madrid.org \\ IES Juan de Herrera \\ Ctra. Guadarrama s/n \\ 28200 San Lorenzo de El Escorial -Madrid- (España)
}

El artículo que aquí se presenta forma parte de la investigación que se ha llevado a cabo en el Archivo de la Catedral de Segovia y que abarca el periodo en que se edificó dicho monumento que está comprendido entre los años de 1524 y 1685 . La edificación de la Catedral de Segovia se constituyó desde su inicio como una obra colectiva pues en su financiación participaron todos los estamentos y grupos sociales de la ciudad. Para ello utilizaron diferentes instrumentos entre los que destacan las ofrendas por el volumen monetario que supusieron pero, también, porque representan el grado de compromiso de cada estamento en la edificación del nuevo templo.

Palabras clave: Catedral de Segovia, financiación, ofrendas, siglos XVI y XVII.
This article, which is being introduced here, is a part of the investigation, which has been carried out in the archives of the Cathedral of Segovia. It covers the period in which the monument was being built, from 1524 to 1685 . The building of the Cathedral of Segovia was thought to be a collective one from the beginning, as it received financial support from every statement and social group in the city. Different instruments were used to construct it, among them and significantly important, were the offerings, because of the monetary volume they supposed but also because they represent the degree of compromise of every statement in the construction of the new temple.

Key words: Cathedral of Segovia, financing, offerings, XVI'th and XVII'th century. 


\section{INTRODUCCIÓN}

Dentro de las rentas que administró la Fábrica ${ }^{1}$ de la Catedral de Segovia para la edificación de su templo que se desarrolló entre 1524 y 1699 , este grupo de fuentes de recursos que aquí se analiza es uno de los que presenta mayor interés en su estudio, por dos razones fundamentales: la primera porque las ofrendas constituyeron la fuente de recursos más importante, cuantitativamente, para la construcción de la catedral; la segunda porque los detalles de las ofrendas regularizadas van a constituir un espléndido indicador del grado de compromiso en la edificación del nuevo templo que tuvo cada estamento de la ciudad.

Por tanto, se van a estudiar en este artículo el grupo de fuentes de recursos que forman las ofrendas, surgidas todas ellas ex novo con motivo de la construcción de la catedral, y entre las que cabe diferenciar fundamentalmente cuatro orígenes: la dotación de los monarcas, las ofrendas de las instituciones religiosas, las ofrendas de estamentos de la ciudad y, fundamentalmente, las ofrendas de los oficios o gremios. A continuación, se describirán detalladamente cada uno de los ocho tipos de ofrendas regularizadas a favor de la Fábrica de la catedral segoviana que fueron registradas en los libros de esta institución.

\section{MONARCAS}

Muy modesta fue la aportación de los reyes a la construcción de la catedral. Es necesario, sin embargo, diferenciar claramente la aportación directa de dinero por parte de los monarcas asignando a la obra cantidades que, de otro modo, habrían quedado a disposición de la hacienda real; de la colaboración indirecta de los reyes concretada en la concesión de "facultades de sisa"2 que los reyes otorgaron a favor del ayuntamiento de la ciudad para que éste pudiera recaudar la limosna institucionalizada que hacía a la obra (García Sanz 1985: 197). Este dinero, aunque en realidad salía del bolsillo del ciudadano de a pie, sirvió de

\footnotetext{
"Fábrica es el nombre que recibe el organismo encargado de la administración de los bienes y rentas pertenecientes a una determinada iglesia" (Aldea 1973: 1.007).

2 "Impuesto que se cobraba sobre géneros comestibles, menguando las medidas" (RAE 1992: 1.887)
} 
excusa histórica a monarcas y Ciudad para atribuirse una participación significativa en la financiación de la nueva catedral.

La aportación directa de dinero por parte de los reyes fue, en efecto, muy escasa a pesar de que Carlos I apareciera en un principio como el gran impulsor de la obra; en realidad su motivación era exclusivamente militar, pues deseaba destruir del todo el antiguo templo catedralicio con el fin de tener más protegida la fortaleza del Alcázar ante posibles problemas de tipo bélico. Así, el emperador prometió mucho con el fin de iniciar la demolición cuanto antes pero pagó poco. Comprometió la entrega inmediata a la Fábrica catedralicia de 4.000 ducados -1.500 .000 maravedís (mrs.)- en la primera bula de San Pedro, entre 40.000 y 50.000 ducados en las cuestaciones echadas de la bula de la Cruzada, y 1.200.000 mrs. en cuatro años a cobrar en la Casa de Contratación de la Especiera que se iba a fundar en La Coruña. De todo esto el fabriquero ${ }^{3}$ de la catedral sólo cobró los 4.000 ducados de la bula de San Pedro y con dificultad ya que hasta 1544 no se llegó a completar el cobro de esa cantidad. Además, por encima de $90.000 \mathrm{mrs}$. se gastaron infructuosamente en intentar el cumplimiento de las otras promesas realizadas, por lo que la cifra final atribuible al emperador queda fijada en $1.410 .000 \mathrm{mrs}$. de los $21.450 .000 \mathrm{mrs}$. prometidos.

Peor le resultó a la economía de la Fábrica Felipe II y eso que frecuentó Segovia con bastante asiduidad, lo que siempre suponía un enorme desembolso para la Ciudad y el cabildo en ornamentos y arreglos varios en toda la villa, y, por supuesto, en las inevitables fiestas para el monarca. Entre estas visitas destacó la efectuada cuando en 1570 contrajo nupcias en la capilla del Alcázar con Ana de Austria. La edificación de la catedral sólo recibió de él una manda para la catedral de $959.315 \mathrm{mrs}$. (4.000 pesos de plata de las Indias) que otorgó en 1568.

Descendiendo en la dinastía ni un solo maravedí se logró ni de Felipe III ni de Carlos II para la Fábrica catedralicia segoviana. Únicamente de Felipe IV se obtuvieron dos cédulas para cobrar a favor de la Fábrica 8.000 ducados -4.000 ducados por cada cédula- en el feblaje (merma del peso de la moneda de vellón) de la Casa de la Moneda de Segovia. La primera cédula data de 10 de diciembre de 1624 y se refundió en otra de 29 de marzo de 1628. La segunda cédula data de 14 de enero

3 "La administración de los bienes de la Fábrica se encomendaba a un fabriquero, mayordomo u obrero, generalmente canónigo" (Teruel 1993: 207). 
de 1635 y en su concesión concurrieron circunstancias que merecen ser recordadas (García Sanz 1985: 198). Ocurrió que un tal doctor Antonio Lauro, genovés avecindado en Segovia, había inventado un ingenio:

...para limpiar los paños de lana y sacar de ellos el azeite y apartarle del agua y hazer jabón... sin que recivan -los paños- el daño que agora reçiven en la manera que los limpian que será en beneficio público destos Reynos, de los haçedores y fabricantes de dichos paños... (Archivo de la Catedral de Segovia, caja F-34).

Al obispo de Segovia, don Melchor de Moscoso, decidió adquirir a perpetuidad y a beneficio de la Fábrica el derecho de explotar "el ingenio", pagando por ello al rey el servicio de 7.000 ducados 2.625.000 mrs.-, cantidad que pensaba aportar de su peculio particular. Como de momento no disponía de esa suma, indujo al cabildo para que la Fábrica tomara a censo esa cantidad lo que, en efecto, se hizo, recibiendo la hacienda real esos 7.000 ducados en varios pagos realizados en 1630 y 1631 . Una serie de desgracias ocurrieron a continuación: por una parte, murió el prelado dejando deudas, por lo que la Fábrica sólo logró cobrar 4.868 ducados del expolio del obispo y no pudo redimir el censo; por otra, fracasaron las esperanzas puestas en la rentabilidad del "ingenio" de Lauro ya que

...antes de goçar cosa alguna pereció del todo el artificio por aver allado los mercaderes otro modo de sacar el aceyte y labar la ropa a menos costa y más probecho de los paños... (Archivo de la Catedral de Segovia, caja F34).

A resultas de la desafortunada iniciativa episcopal, la Fábrica era deudora en 1634 de 8.400 ducados entre el principal y los réditos corridos del censo, y no disponía de recursos para superar esta grave situación. Por eso acude al rey y obtiene de él la mencionada cédula de 1635 como indemnización parcial por el "servicio" pagado. Sin embargo, hasta 1653 no percibió la Fábrica dinero alguno en virtud de las dos cédulas sobre el "feble" de la Casa de la Moneda otorgados por Felipe IV. Y entre 1653 y 1675 recaudó sólo 7.118 ducados -2.669 .246 mrs.- de los 8.000 concedidos.

En conclusión, si de la suma de las aportaciones directas de los reyes se restan las cantidades que costaron cobrarlas y los "servicios" otorgados por la Fábrica a la hacienda real resulta que los cobros netos para la obra por este concepto no alcanzan 2'5 millones de maravedíes, y 
hubo muchos años en que se gastó más de esa cantidad en la obra; si tenemos en cuenta que la obra se dilató por espacio de ciento setenta y cinco años se comprende que se califique de "muy modesta" la dotación de los monarcas. Y no hay que sorprenderse de ello pues de todos son sabidas las penurias y estrecheces que padeció la hacienda real castellana en los siglos XVI y XVII.

Sin embargo, habría que ser más duros a la hora de calificar en este análisis la aportación regia. No es que los monarcas estuvieran obligados a participar en la construcción de la catedral de una de sus ciudades, lo que hacía singular a la obra de la catedral de Segovia, respecto a las ayudas económicas de los reyes, es que se trataba de una obra impulsada y poco menos que impuesta por el emperador, ya que al cabildo y al conjunto de los segovianos les hubiera resultado mucho más fácil acometer la reparación del antiguo templo, que en el más inflado de los presupuestos suponían siete millones de maravedíes, que construir uno nuevo cuyo montante final superaría con creces los doscientos millones. Por lo tanto, si su responsabilidad era mayor como promotores de la obra y sus ofrendas representaron apenas el 1'8 \% del total de las que recibió la Fábrica catedralicia, más que de modesta sería mejor calificar de insuficiente la aportación regia, y de error la decisión de construir un nuevo templo, con el sufrimiento y agotamiento de muchos recursos de la ciudad a costa, además, de destruir totalmente una joya arquitectónica del románico como era la antigua catedral de Santa María de Segovia, situada frente al Alcázar.

\section{CIUDAD}

El origen de la ofrenda del ayuntamiento o Ciudad estuvo en que esta institución, que representaba también a la Tierra ${ }^{4}$ o circunscripción rural sometida a la jurisdicción de la Ciudad, se reconoció responsable de la destrucción de la antigua catedral durante la Guerra de las Comunidades; en consecuencia, se comprometió a pagar los desperfectos al cabildo. Estos se valoraron en algo más de siete millones

La Tierra de Segovia se divide en nueve sexmos (demarcaciones trazadas en la geografía del concejo con un fin administrativo y fiscal): Posaderas, Santa Eulalia, San Martín, Cabezas, San Millán, San Lorenzo, La Trinidad, Lozoya y Casarrubios. González (1971) y Asenjo (1986: 91). 
de maravedíes tras un breve litigio ${ }^{5}$. Como a la hacienda municipal le resultaba imposible realizar tal desembolso, dado que debía atender a otras "reparaciones de guerra", la cosa quedó en que pagaría sólo tres millones de maravedíes en los diez años inmediatos y en el compromiso de que

...pasados los dichos diez años Ciudad y Tierra ayudarían siempre a la dicha iglesia pues tenía a ello obligación (Archivo de la Catedral de Segovia, caja G-60).

La Ciudad hizo honor a este compromiso y mantuvo su aportación durante todo el tiempo que duró la obra pero, conviene recordar, como se apuntó más arriba, que la cantidad que anualmente la Ciudad entregaba a la Fábrica era recaudada en virtud de específicas facultades para echar sisas sobre el consumo de aceite y jabón especialmente concedidas por los monarcas con este objeto y que, cuando la Ciudad no contaba con tales facultades, dejaba de aportar su ofrenda. Es más, afirmaba el primer fabriquero Juan Rodríguez que para la Ciudad fue harto provechosa su limosna, porque obtenía de las sisas bastante más dinero del que ofrendaba, disponiendo así, con el pretexto de la contribución a la obra, de una fuente adicional de ingresos para las arcas municipales (Díaz-Miguel 1968: 222). Tal vez esto ayudó a los recelos mutuos entre cabildo y Ciudad que recogieron numerosos documentos de la época, y que también aparecen reflejados en los libros de Fábrica de la catedral.

Un breve análisis de estos desacuerdos puede ser útil para comprender las actitudes mentales y políticas en que es preciso inscribir la práctica de la limosna y de las ofrendas regularizadas. El ayuntamiento de Segovia, la Ciudad, fue la institución que más hostigó en este sentido al cabildo. Ya en 1561, transcurridos treinta y seis años desde el comienzo de la edificación, el fabriquero tuvo que justificar el ritmo de las obras, demasiado lento a juicio de los regidores del ayuntamiento. En 1612 la Ciudad se siente herida por la decisión del cabildo de colocar sólo las armas, o escudo, de éste en la portada de San Frutos. El cabildo respondió alegando que aún faltaban por colocar dos escudos en la portada y que uno de ellos sería el correspondiente a la Ciudad y el otro al del cabildo (García Sanz 1985: 206). Pero el conflicto más grave surgió en 1628, cuando la Ciudad exigió al cabildo que le entregara una llave del

5 Recogido pormenorizadamente por Cortón (1997: 43-44). 
arca donde se guardaban las ofrendas que recibía la Fábrica para investigar cómo se gastaban las mismas. El cabildo se irritó ante esta pretensión por el ataque que suponía a su reputación la actitud del ayuntamiento. Además, el cabildo creía que esto había de redundar en el rápido descenso de las ofrendas. La Ciudad respondió que se sentía obligada a tomar esa resolución para evitar precisamente que decayeran las limosnas dando satisfacción a la población, ya que había llegado a su conocimiento que en el pueblo había sentimiento y murmuraciones de que la dilación de la Fábrica y su moderado lucimiento era debido a que las limosnas no se dedicaban en su totalidad a la obra de construcción del nuevo templo catedralicio (García Sanz 1985: 206).

De principios de diciembre de 1628 a mediados de febrero de 1629 las relaciones entre el ayuntamiento y el cabildo se hicieron sumamente tensas. El ayuntamiento indujo a los gremios a que no entregaran limosnas en la catedral y los regidores dejaron de asistir a las ceremonias religiosas en calidad de representantes de la Ciudad. Sin embargo, como era previsible, al fin se llegó a una concordia en virtud de la cual el cabildo reconocía el derecho de la Ciudad a supervisar el destino dado a todas aquellas ofrendas y limosnas entregadas con la finalidad precisa y clara de financiar la construcción de la catedral, pago de materiales y salarios de obreros. $Y$ es que hasta entonces, y ello justificaba la actitud del ayuntamiento, el dinero entregado explícitamente para la obra entraba a formar parte indiferenciada del conjunto de los cobros de la Fábrica y el cabildo lo aplicaba a aquella finalidad que, a su juicio, más convenía a la propia Fábrica.

Sin embargo, los períodos de desavenencia entre el ayuntamiento y el cabildo se alternaban con etapas de perfecta concordia y hasta de colaboración efectiva. Tal ocurría, sobre todo, cuando el ayuntamiento se veía obligado a reclamar el apoyo de los prebendados para arrancar del rey la renovación de la facultad para echar sisas con que recaudar el dinero de su ofrenda. A pesar de todo lo anteriormente comentado, la aportación de la Ciudad a través de su ofrenda regularizada y de las sisas excepcionales que realizó a favor de la Fábrica catedralicia constituyó la partida económica más importante de las rentas de la Fábrica durante el conjunto de años que duró la construcción de la nueva catedral. Así, la ofrenda de la Ciudad, del conjunto de años de los que se tienen datos (no se hayan actualmente en el Archivo de la Catedral de Segovia los libros de Fábrica referidos al intervalo 1576-1603), asciende en total a sesenta millones de maravedíes; lo que supone, en términos 
porcentuales, más del 45 ’2\% de todas las ofrendas que recibió la Fábrica $\mathrm{y}$, trasladado al global de fondos que se recaudaron para el nuevo templo catedralicio, casi una quinta parte de los cobros totales que obtuvo esta institución durante la construcción. Con esta perspectiva, parecen más lógicos los recelos y desavenencias descritos entre los responsables del cabildo y el ayuntamiento de la ciudad sobre la marcha de las obras y el destino de lo recaudado, teniendo en cuenta, además, que las rentas ordinarias, cuestaciones y ofrendas religiosas se aplicaron siempre a los gastos ordinarios de la propia Fábrica, los cuáles consistían básicamente en todos los necesarios para oficiar la liturgia religiosa en el interior del templo (en la parte ya construida) pero que crecieron ${ }^{6}$ de manera desmesurada a lo largo del periodo analizado.

\section{OBISPOS}

De la aportación de los obispos cabe decir que fue más irregular de lo esperado puesto que no se hizo efectiva en largos períodos de tiempo. Sin duda, el cabildo y el fabriquero actuaron con más comprensión y condescendencia frente a sus prelados morosos que, por ejemplo, frente a la Ciudad cuando tenían que exigir el cumplimiento de sus respectivos compromisos, en muchos casos sin éxito. La plaza de obispo de Segovia resultaba ser un excelente trampolín en la carrera religiosa de los prelados ya que de aquí acostumbraban a salir nombrados para otros obispados más importantes o, incluso, arzobispados; si a esto se une la corta esperanza de vida de la época, se entiende que por el obispado de Segovia pasaran en el período analizado más de treinta obispos. Evidentemente, el compromiso personal con el cargo y con el templo varió mucho de unos a otros, de ahí lo irregular de sus aportaciones. En conjunto, sí puede apuntarse que la aportación de los obispos segovianos fue bastante menor de lo que cabía suponerse de los mismos, sobre todo, si se tiene en cuenta la considerable dotación económica que tenía la Mesa episcopal de Segovia. En total, la contribución de la mitra dentro del global de las ofrendas fue del $7 \%$. Sin duda, se podía esperar una mayor participación del primer representante de la jerarquía eclesiástica.

Este aspecto ha sido debidamente detallado y estudiado de los datos extraídos 
Siguiendo el episcopologio ${ }^{7}$ de la diócesis de Segovia realizado por Ángel García y García-Estévez (1998: 244-292), durante el tiempo que duró la construcción del nuevo templo catedralicio, se tratará de presentar la cantidad aportada por cada uno de sus obispos a la Fábrica. Si bien, hay que tener en cuenta que aunque apareciera en los libros de Fábrica contabilizada la ofrenda regular del obispo de turno, esto no significaba obligatoriamente que ésta hubiera sido realmente entregada en ese momento ya que, en no pocas ocasiones, había que esperar a realizar el expolio de sus bienes para proceder al cobro definitivo de las mismas. Hecha esta salvedad, podría presentarse la siguiente relación:

- Diego de Ribera: natural de Toledo, estudió en Salamanca y fue obispo de Mallorca desde 1507 hasta 1511. El 29 de octubre de este año fue preconizado como obispo de Segovia tomando posesión el 15 de marzo de 1512. Estuvo ausente de su obispado durante la Revuelta de las Comunidades. Al volver, ante el mal estado de la catedral, se queda en la iglesia de Santa Clara y promueve la construcción del nuevo templo. El 24 de mayo de 1525 dio tres azadonadas para principio de los cimientos y el 8 de junio siguiente bendijo la colocación de la primera piedra. Estuvo al frente de la diócesis hasta su muerte el 6 de febrero de 1543, desconociéndose tanto el lugar de su fallecimiento como el de su sepultura. Este obispo mantuvo un alto grado de compromiso con la obra durante todo su mandato efectuando una aportación anual de $75.000 \mathrm{mrs}$. por lo que su contribución total ascendió a $1.050 .000 \mathrm{mrs}$.

- Antonio Ramírez de Haro: natural de la provincia de Cuenca, fue obispo de Orense, después de Ciudad Rodrigo, de Calahorra y finalmente de Segovia, siendo preconizado el 6 de agosto de 1543 y tomando posesión el 15 de diciembre de ese mismo año. En 1549, hallándose de visita en el Real Convento de las Huelgas de Burgos, fallece a 16 de septiembre, siendo sepultado en la iglesia del Hospital Real de los frailes de Calatrava anejo al Convento de las Huelgas. Su aportación a la obra fue también importante pues contribuyó con 506.929'5 mrs.

- Gaspar de Zúñiga y Avellaneda: natural de Osma (Soria) e hijo de los condes de Miranda, estudió en Salamanca donde obtuvo una 
cátedra de Teología. El 27 de junio de 1550 fue nombrado en Roma obispo de Segovia, habiendo sido propuesto por Carlos I por insinuación de Domingo de Soto que había renunciado a ocupar el cargo. Su entrada en Segovia tuvo lugar el 24 de septiembre de ese año. Fue al Concilio de Trento en 1551 y asistió a las dos últimas sesiones, regresando a Segovia el 20 de diciembre de 1552. El 21 de julio de 1558 fue preconizado arzobispo de Santiago de Compostela, tomando posesión el 11 de febrero de 1559; pero antes, el 15 de agosto de 1558, y por deseo expreso suyo, se produjo el traslado de los oficios del templo de Santa Clara a la nueva catedral. Su contribución a la obra catedralicia supuso un total de 253.206'5 mrs. para la Fábrica.

- Fray Francisco de Benavides: hijo del Mariscal de Castilla. Siendo obispo de Mondoñedo fue promovido el 21 de octubre de 1558 al obispado de Segovia, tomando posesión el 28 de enero de 1559. Su estancia fue breve pues murió el 15 de mayo de 1560 cuando había sido promovido para el obispado de Jaén del que no llegó a tomar posesión. Sólo queda constancia en los libros de una ofrenda del obispo en 1559 por valor de 37.485 mrs.

- Martín Pérez de Ayala: natural de la provincia de Jaén, fue obispo de dos diócesis: Guadix, Segovia y, posteriormente, arzobispo de Valencia. En Segovia estuvo en el cargo de 1560 a 1564; en concreto, llegó a la ciudad el 25 de abril de 1561 pero había tomado posesión el 31 de octubre de 1560. Su estancia fue polémica al tratar de organizar la residencia de los clérigos del cabildo conforme a las normas del Concilio tridentino lo que le hizo acreedor de la oposición del cabildo catedralicio. Como consecuencia de estos enfrentamientos mandó encarcelar en la fortaleza de Turégano y en la cárcel de Fuentepelayo al escribano y notario de la catedral, respectivamente. Partió de la ciudad el 7 de diciembre de 1564, dejando para la Fábrica catedralicia un total de 288.644 mrs. en ofrendas.

- Diego de Covarrubias y Leyva: nacido en Toledo en 1512, estudió cánones en Salamanca donde recibió el grado de doctor en 1538. Fue profesor de la universidad, posteriormente oidor en la Chancillería de Granada y obispo de Ciudad Rodrigo. El 3 de agosto de 1564 fue propuesto para la sede de Segovia, tomando posesión el 1 de enero de 1565. En 1572 fue nombrado Presidente del Consejo de Castilla, cargo que compaginó con el obispado segoviano hasta 
1577, año en que murió a 6 de septiembre. Su sepulcro se halla en la catedral segoviana con una espléndida estatua yaciente de alabastro. Sólo ha sido posible obtener los datos de ofrendas referidos hasta 1575 por la ausencia de libros de Fábrica para el periodo comprendido entre 1576 y 1603, no obstante hasta ese momento había aportado a la construcción del nuevo templo catedralicio un total de $\mathbf{4 1 0 . 5 0 0} \mathrm{mrs}$.

Esta ausencia de libros de Fábrica afecta a seis prelados de los que no ha sido posible concretar su aportación a la edificación de la catedral y que, por orden, son: Gregorio Gallo, Luis Tello Maldonado, Andrés de Cabrera y Bobadilla, Francisco de Ribera y Ovando, Andrés Pacheco y Maximiliano de Austria.

- Pedro de Castro y Nero: natural de la provincia de Palencia, nació en 1541. Siendo obispo de Lugo fue promovido al obispado segoviano el 13 de agosto de 1603, tomando posesión el 28 de septiembre. Fue famoso por su caridad y continuo ejemplo cristiano. Murió el 28 de octubre de 1611 y fue sepultado entre los dos coros de la catedral. Con la aparición de los libros de Fábrica de la catedral vuelve a ser posible extraer su contribución a la obra que ascendió a 320.000 mrs., a razón de 40.000 mrs. anuales.

- Gómez de Figueroa: siendo obispo de Cádiz, fue presentado para el obispado segoviano pero murió sin llegar a tomar posesión de la diócesis.

- Antonio Idiáquez Manrique: natural de Madrid, era hijo del Secretario del Consejo de Italia. Estudió teología en Alcalá y Salamanca de donde fue rector. A los pocos años fue canónigo de Segovia, arcediano de Sepúlveda y también arcediano de Segovia. En 1610 fue promovido como obispo de Ciudad Rodrigo donde permaneció hasta que fue preconizado obispo de Segovia el 4 de febrero de 1613, tomando posesión el 27 de mayo y entrando en la ciudad al día siguiente. Contribuyó con 6.000 ducados a reparar el incendio de la catedral ocurrido como consecuencia de un rayo el 18 de septiembre de 1614, además de los 120.000 mrs. entregados en sus ofrendas de tres años. Murió el 17 de noviembre de 1615 y está enterrado en la Capilla del Cristo de la catedral.

- Juan Vigil de Quiñones: nacido en 1546 en Montaña, estudió derecho en Salamanca. Vino a Segovia procedente del obispado de Valladolid, 
entrando en la ciudad el 25 de octubre de 1516. A los diez meses y seis días de su entrada falleció cuando contaba 72 años de edad. En los libros de Fábrica aparecen recogidas las ofrendas de la Mesa episcopal de los años 1616 y 1617 de 40.000 mrs. cada una, por lo que parece que ésta fue su participación en la obra.

- Francisco de Sosa: siendo obispo de Osma fue promovido al obispado segoviano sin que llegara a tomar posesión del mismo al fallecer el 9 de enero de 1618. También aparece recogida en el libro de Fábrica de 1618 una ofrenda del obispo por valor de $40.000 \mathrm{mrs}$. aunque es más que probable que la misma no se hiciera efectiva por la repentina muerte del prelado.

- Alonso Márquez de Prado: nació en El Espinar (Segovia) en 1557. Estudió en Ávila y Salamanca. En 1593 fue nombrado Inquisidor de Barcelona y poco después fiscal de la Suprema Inquisición. Posteriormente, fue obispo de Tortosa, Cartagena y Segovia, tomando posesión el 25 de septiembre de 1618 y entrando en la ciudad el 7 de octubre. Murió el 7 de noviembre de 1621, siendo sepultado entre los coros de la catedral; $120.000 \mathrm{mrs}$. aportó en los tres años en que estuvo en posesión de la mitra segoviana.

- Fray Iñigo de Brizuela: nació en Berlanga y estudió en Salamanca, fue confesor del archiduque Alberto. En mayo de 1622 fue preconizado para el obispado de Segovia. Sin embargo, tuvo problemas con el voto y juramento que tenía el estatuto del cabildo segoviano, por lo que renunció al cargo en 1624 sin haber llegado a tomar posesión del mismo. A pesar de ello, sigue apareciendo recogida la ofrenda anual de 40.000 mrs. en los libros de Fábrica de 1622 y 1623.

- Melchor de Moscoso y Sandoval: hijo de los condes de Altamira, estudió teología en Salamanca. Fue preconizado para el obispado segoviano el 29 de mayo de 1624. Se distinguió por sus obras de caridad, especialmente durante la gran falta de pan que acaeció en la ciudad en 1632, año en el que falleció. Su aportación a la construcción de la nueva catedral fue de $480.000 \mathrm{mrs}$. aunque pasaría a la posteridad por el coste que le supuso a la Fábrica una iniciativa empresarial suya, anteriormente citada y por la separación que se produjo entre las cuentas de la Fábrica y las de la obra en 1629 siendo él obispo de la diócesis.

- Álvaro de Benavides: natural del obispado de Jaén, era hijo del conde de Santisteban. Felipe IV le dio la presidencia de la Chancillería de 
Granada y el priorato de Aroche. El 8 de diciembre de 1632 fue presentado para el obispado de Segovia; tras ser preconizado el 18 de julio de 1633, tomó posesión el 12 de diciembre de este año. De Segovia fue trasladado a Cartagena el 19 de noviembre de 1640. Debido al agrupamiento de las cuentas de la Fábrica entre los años de 1636 a 1646 es imposible saber la aportación concreta de este prelado y que aproximadamente ascendió a 308.500 mrs.

- Fray Pedro de Tapia: nació en 1582 en Villoria (Salamanca). Estudió leyes y cánones, y fue Calificador del Consejo Supremo de la Inquisición. El 24 de agosto de 1640 fue presentado para el obispado de Segovia, tomando posesión el 15 de junio de 1641 y entrando en la ciudad el 15 de agosto. Durante este período su participación en las rentas de la Fábrica ascendió aproximadamente a 162.500 mrs. En 1644 fue promovido a Sigüenza.

- Pedro de Neyla: natural del obispado de Soria, fue preconizado obispo de Segovia el 12 de junio de 1645. Murió en 1648 por lo que su participación en la construcción de la catedral fue de 120.000 mrs.

- Francisco de Araujo: nació en Galicia en 1580 y además de teólogo fue un gran filósofo. El 13 de enero de 1648 fue preconizado obispo de Segovia, sede a la que renunció en 1656, retirándose a un convento de Madrid. Durante el período de tiempo que fue poseedor de la Mesa episcopal su aportación a las cuentas de la Fábrica ascendió a 400.000 mrs.

- Juan del Pozo: nacido en Segovia, además de obispo fue un excelente escritor y orador. Rigió la diócesis segoviana desde el 28 de agosto de 1656 hasta su fallecimiento el 16 de agosto de 1660. Participó con $160.000 \mathrm{mrs}$. en la construcción del nuevo templo.

- Francisco de Zárate y Terán: fue preconizado obispo de Segovia el 21 de febrero de 1661. Tuvo diferencias con el cabildo sobre determinadas prebendas, llegando el pleito a Roma. Fue trasladado a Cuenca el 28 de enero de 1664. Su participación estuvo cercana a los $150.000 \mathrm{mrs}$.

- Diego de Escolano y Ledesma: nació en Madrid en 1609 y estudió en El Escorial, Alcalá y Salamanca, donde dejó numerosas obras escritas. Fue obispo de Mallorca y Tarazona antes de ser preconizado a Segovia el 17 de marzo de 1664. Permaneció en esta diócesis 
hasta 1668, año en el que fue trasladado al arzobispado de Granada. Es difícil precisar su participación en las finanzas de la Fábrica pues desde 1664 y hasta 1675 aparece un único apunte contable que recoge las ofrendas del obispo y del cabildo de forma conjunta; no obstante, es más que probable que siguiera siendo de 40.000 mrs. anuales.

- Jerónimo Mascareñas: nació en Lisboa, estudió en Coimbra y fue Consejero Real de Portugal. Cuando la revolución de 1640 contra la Corona española se puso del lado de ésta por lo que el rey de España le nombró obispo de Leiria, prior de Guimaraes y sumiller de la Cortina. El 9 de abril de 1668 fue preconizado obispo de Segovia, donde fallecería el 25 de octubre de 1671. Al igual que con su antecesor en el cargo, es imposible concretar su aportación a la obra de la catedral.

- Matías de Moratines y Santos: era obispo de Astorga cuando fue preconizado al obispado segoviano el 3 de octubre de 1672, tomando posesión el 22 de diciembre de 1672 y falleciendo en septiembre de 1682. Durante su mandato se incrementó significativamente la ofrenda del obispo de Segovia a la Fábrica catedralicia, y su compromiso con la obra del nuevo templo fue uno de los mayores de todos los prelados que pasaron por este obispado desde el inicio de la construcción pues su participación superó los dos millones de maravedíes. Sin duda la cercanía del final de la edificación influyó también en el ánimo de los poseedores de la mitra segoviana.

- Francisco Antonio Caballero: Presidente de la Chancillería de Valladolid fue preconizado obispo de Segovia el 8 de marzo de 1683, año en el que murió.

- Andrés de Angulo: inquisidor de Valencia y Sevilla, tomó posesión del obispado segoviano el 30 de mayo de 1685, falleciendo dos años más tarde. Su aportación a la obra estuvo cercana a los $500.000 \mathrm{mrs}$. El 8 de junio de 1686 en solemne ceremonia presidida por el obispo se descubriría por fin el crucero y se abriría al culto la Capilla Mayor de la catedral.

- Fernando Guzmán: preconizado obispo de Segovia el 29 de noviembre de 1688, tomó posesión el 14 de febrero de 1689 y murió en agosto de 1694. Contribuyó a la finalización del templo catedralicio con unos $300.000 \mathrm{mrs}$. 
- Bartolomé de Ocampo y Mata: natural de Madrid. Fue preconizado obispo de Segovia el 8 de noviembre de 1694, cargo en el que estuvo hasta su traslado a Plasencia el 1 de junio de 1699. Este último obispo del período analizado tuvo una aportación a la definitiva conclusión de la catedral de alrededor de 323.600 mrs.

El siguiente prelado no llegaría a la diócesis segoviana hasta abril de 1700.

\section{CABILDO Y CLERECÍA}

El cabildo y el clero capitular fueron los benefactores de la obra que con mayor puntualidad y constancia pagaron sus ofrendas, y se comprende que así fuera por el deber que tenían de dar ejemplo al resto de los habitantes de la ciudad, por la dependencia que tenían con el obispo y, sobre todo, por la necesidad que tenían de ver terminado el templo catedralicio pues en su interior desarrollaban la inmensa mayoría de sus actividades diarias. Con mayor irregularidad se comportó la clerecía $^{8}$ de la ciudad, que sólo dio modestas ofrendas en los primeros años de la construcción y luego entre 1604 y 1634 según se desprende de los libros de Fábrica. Sin embargo, su aportación conjunta supuso más del doble que la de los obispos, por lo que se puede concluir que realmente realizaron un esfuerzo considerable a favor del templo catedralicio. En cifras, la aportación conjunta de estas dos instituciones supera los veintitrés millones de maravedíes en los años de los que se disponen de libros de Fábrica de la catedral; en porcentaje, supone más del $17 \%$ de las ofrendas recibidas por los fabriqueros. Este porcentaje final es difícilmente interpretable pues dentro de estos dos grupos religiosos, que sumaban más de centenar y medio de personas, también existían enormes diferencias económicas que iban de los grandes sueldos de los canónigos catedralicios a los más pequeños de los curas de las parroquias humildes y a los prácticamente inexistentes de los monjes de la ciudad. Por tanto, es normal que la contribución del cabildo suponga el $96 \%$ del total aportado por estas dos instituciones. 


\section{LINAJES}

La Junta de Nobles Linajes o como se la denomina en la propia documentación utilizada, "los Linajes", era una institución que agrupaba a lo más granado de las familias nobles segovianas, muchas de ellas descendientes de la nobleza repobladora de los siglos XI y XII. La Junta era copropietaria con la Ciudad y Tierra de extensas fincas rústicas, entre las que figuraba el formidable pinar de Valsaín. Era de la renta que obtenía la Junta por el arrendamiento de esta finca de donde procedía la ofrenda que entregaba a la Fábrica. Por otra parte, el estamento nobiliario de la ciudad en su conjunto aportaba limosna en la ofrenda llamada de los Caballeros que, como la de los Linajes, era bastante modesta ya que, en conjunto, supuso la mitad de participación que los obispos. En concreto, las ofrendas de los Linajes supusieron sólo el 3'1\% de la recaudación de este grupo de rentas de la Fábrica.

Aunque en su descargo podría argumentarse su pequeño número, pues no llegaban a sumar cien vecinos, en su contra cabría decir que aglutinaban una enorme riqueza basada en las rentas que obtenían de tierras, rebaños y casas repartidas por el alfoz de Segovia, además del ya citado arrendamiento de la explotación maderera del pinar de Valsaín. En efecto, si se sustraen las posesiones de la Iglesia, los pocos labradores que eran dueños de sus tierras, y la riqueza generada por la industria textil, de la que no participaban por prejuicios relacionados con las actividades manuales, toda la riqueza de la ciudad y de los numerosos territorios que de ella dependían les pertenecían; eran unas posesiones tan grandes que a su lado, su aportación a la construcción del templo, del que luego se enorgullecían, cabría de calificarla de miserable.

\section{GREMIOS}

Las ofrendas de los gremios de los oficios constituyen el capítulo que presenta mayor interés por ser los datos que mejor reflejan la coyuntura económica de la ciudad tanto en su etapa de prosperidad como en la posterior decadencia. Además, hay que tener en cuenta que la inmensa mayoría de la población de la ciudad contribuía a la obra del nuevo templo utilizando este cauce. No obstante, durante los primeros años de construcción de la catedral el común de los segovianos también solía colaborar en la obra aportando su propio trabajo físico en la apertura de cimientos y en el traslado de los sillares del viejo claustro de la 
antigua catedral al nuevo emplazamiento, operación ésta que se denominó echar piedra.

Ya en 1526 figuran como oferentes de las limosnas los colectivos de menestrales de los tejedores, los pecheros o pelaires y los peinadores-cardadores y zurradores, oficios todos ellos pertenecientes a la industria pañera. Las ofrendas de los menestrales encauzadas por las parroquias fueron languideciendo mientras aumentaban las que se formalizaban por medio de las organizaciones laborales. El día señalado para entregar la ofrenda era jornada festiva para el gremio en cuestión, cuyos miembros acudían en procesión a la catedral portando cada uno de ellos las monedas que deseaban entregar, así como la vela que ofrendaban. A veces, también ofrecían angarillas de arena y cal, o carros de piedra. Durante el primer período de las obras la vistosidad de estos desfiles de oficios debió ser notable como se puede apreciar por la siguiente descripción de la ofrenda que hicieron en el año 1532 los mercaderes de feria:

Domingo XVIII de agosto salieron los mercaderes feriantes y sacaron más de trescientas angarillas y traxeron cierta invención de dançantes unos vestydos de ombres e otros vestydos como mugeres e otros como donzelas, e otros como biudas e dos como reyes de armas que declaraban la ynvención que hera cómo las mugeres e fijas de los mercaderes e las biudas aprovando la limosna de sus maridos desyan qué quantía venya con ellos y las biudas trayan tres velas de cera blancas grandes... (Archivo de la Catedral de Segovia. Libro de Fábrica 1530-1533).

Los oficios que entre 1526 y 1690 ofrecieron limosnas corporativamente, estuvieran constituidos formalmente en gremio o se asociaran excepcionalmente para la ocasión, fueron los siguientes, indicando el nombre que recibía la ofrenda, el día que se realizaba y el punto de origen de sus respectivas procesiones:

- Apartadores de lana, peinadores y cardadores el primer domingo de octubre salían en procesión desde la iglesia de la Trinidad hasta la catedral para entregar allí su ofrenda gremial.

- Tejedores, aunque desde 1635 ofrendarían separadamente los tejedores de "lo ancho" y los tejedores de "lo angosto", el día de San Juan desde el convento de la Trinidad.

- Pelaires, aunque entre 1610 y 1616 ofrendarían separadamente los pelaires de "casa y tienda" de los pelaires "de hermandad", el día de Santiago desde la iglesia de la Trinidad. 
- Tundidores "maestros", zurcidores y apuntadores, el día siguiente a San Roque desde la Trinidad.

- Tundidores de "hermandad" u oficiales, el día de San Bartolomé desde el convento de San Antonio el Real.

- Sastres, calceteros, roperos, jubeteros, cordoneros, sombrereros y aprensadores, que recibían en conjunto el nombre de ofrenda de "la tijera", el día de la Natividad de Nuestra Señora, ocho de septiembre, desde la iglesia de San Juan.

- Monederos y ministros mayores y menores de la Casa de la Moneda, hacían su ofrenda en la fiesta de la Purificación, el 2 de febrero, desde la iglesia de San Sebastián.

- Zapateros, pergamineros, pellejeros, corambreros, curtidores, zurradores y boteros, denominados ofrenda de "el cuero", el día de la Asunción desde la Trinidad.

- Carniceros, cabriteros, estaderos, pesadores, cocineros, figones y fruteros, cuya ofrenda recibía la denominación de "ofrenda de la carne", el primer domingo de agosto desde la Trinidad.

- Carpinteros, arquitectos, albañiles, mamposteros, escultores, ensambladores, canteros, guarnicioneros, freneros, silleros, jaeceros, pavonadores, aserradores, cabestreros, latoneros, torneros y cedaceros, en conjunto llamados la ofrenda de "el martillo", el día de San Lorenzo desde la Trinidad.

- Arrieros, taberneros, bodegoneros, herradores y olleros, el primer domingo de septiembre desde la Trinidad.

- Molineros, bataneros, panaderos y pasteleros, ofrenda de "la harina", el día de la Ascensión, desde el Convento de la Trinidad.

- Mercaderes y excepcionalmente feriantes; casi siempre hacedores de paños, y con ellos mercaderes de varas, cereros, confiteros y bordadores, el domingo de Cuasimodo, desde la iglesia de San Francisco.

- Los médicos, cirujanos, barberos, boticarios, pintores, plateros y otros oficios que no tenían día señalado se agregaban a la parroquia o nación de cada uno.

La suma de todas estas ofrendas es lo que se denomina genéricamente "ofrenda de los gremios", a la que, además, en los libros de Fábrica se han añadido las de las naciones y las parroquias que 
también ofrecían limosna de forma individualizada. Esto puede que infle un poco los porcentajes de participación de estas partidas en las cuentas de la Fábrica, pero sigue resultando un indicador excelente de la marcha económica de la ciudad. Así, en conjunto estas ofrendas supusieron el 26 ' $4 \%$ de todas estas rentas (algo más de treinta y tres millones de maravedíes); porcentaje bastante significativo, únicamente superado por la ofrenda de la Ciudad. Si a esto se añade el que la mayor parte de esta última ofrenda dependía de las sisas aplicadas sobre el consumo de ciertos productos, es decir, del bolsillo de los habitantes de la ciudad, el porcentaje de la ofrenda de los gremios aún cobra más valor.

\section{NACIONES}

Entre los habitantes de Segovia figuraban con cierta idiosincrasia propia los originarios o descendientes de los territorios de la Montaña ${ }^{9}$ y de Vizcaya, que se habían avecindado en Segovia, sin duda, atraídos por la prosperidad de su industria textil. Constituían las denominadas "nación montañesa" y "nación vizcaína". Ambos colectivos diferenciados ofrendaban limosna, en cuanto tales y no por el oficio que sus miembros ejercieran, el domingo antes de San Andrés la nación de los vizcaínos y el domingo después de San Andrés la de los montañeses. Ambas ofrendas partían desde la iglesia de la Trinidad. Este dato constituye otro indicador significativo de la importancia económica y social que alcanzó la ciudad de Segovia durante el siglo XVI al convertirse en importante foco de inmigración para el resto del Reino. Esto explica, también, el incremento demográfico experimentado por la ciudad en la segunda mitad del XVI.

La singular agrupación de los recién llegados a la ciudad en estas dos denominadas "Naciones" aporta, a su vez, ciertos datos de interés. En primer lugar, la llegada en masa de inmigrantes es una muestra de la mala situación económica y social, agravada por pestes y guerras, que existía en el norte del Reino, principal punto de origen de la inmigración que recibió Segovia, y que les empujó a desplazarse al interior. Por otro lado, la llegada en "aluvión" de estos inmigrantes impidió su integración normal en la población de la ciudad, lo que contribuyó a que siguieran

9 Actual provincia de Cantabria y antes de Santander. 
manteniendo su personalidad propia como lo prueba esta ofrenda individualizada.

Por último, esta masiva entrada de vecinos trajo consigo un crecimiento desordenado en los arrabales de la ciudad que tendría fatales consecuencias en la rápida propagación de la crisis epidémica de finales del siglo XVI y que, de vez en cuando, provocaba desgracias como la descrita en la historia de Segovia del cronista Colmenares (1965: 229) en la que una fuerte tormenta de verano acaecida el veinticinco de agosto de 1543 provocó una enorme crecida de los ríos Eresma y Clamores que arrasaron a su paso más de cuarenta casas que se habían construido junto a su cauce.

\section{PARROQUIAS}

De igual forma que ocurría con las "Naciones", algunas parroquias mantenían también una ofrenda individual a la que se sumaban en ocasiones algunos pueblos cercanos. Así, el segundo día de la Pascua del Espíritu Santo los parroquianos de San Lorenzo salían desde la iglesia del mismo nombre y realizaban su ofrenda a la edificación de la catedral en procesión acompañados por los habitantes de los pueblos de $\mathrm{La}$ Lastrilla, Espirdo, Tizneros, Sonsoto, Trescasas, San Cristóbal, Cavanillas, Tabanera y Palazuelos. Al día siguiente, lo hacían los parroquianos de Santa Coloma saliendo desde su iglesia acompañados por los vecinos de los pueblos de Revenga y Hontoria, además de por los labradores del arrabal mayor. Otro tanto, pero en sentido inverso, cabe decir de la agregación a los oficios de las modestas limosnas que algunas parroquias (básicamente, Santa Columba y Santa Eulalia) siguieron haciendo hasta el final de la obra; y, también, de las limosnas menudas depositadas en los cepos y platos colocados al efecto en la catedral y los templos de la diócesis.

\section{CONCLUSIONES}

En resumen, estas fueron las ofrendas que recibió la Fábrica de la catedral de Segovia para la edificación de su templo:

- El rey: Carlos I impulsó la construcción de la nueva catedral con unas ofrendas que no llegaron a cobrarse en su totalidad y que no 
se consolidaron en ninguno de sus sucesores, salvo algunas aportaciones realizadas de manera muy extraordinaria.

- El ayuntamiento o, también llamado en la documentación manejada, "la Ciudad": esta ofrenda se creó con motivo de la indemnización que tenía que pagar la Ciudad para responder de los destrozos ocasionados en la Revuelta Comunera en la antigua catedral de Santa María. Con el paso de los años se constituyó en la ofrenda más importante y regular que recibió la Fábrica catedralicia. La Ciudad solía hacer coincidir su ofrenda con el día de la Epifanía del Señor. Comenzó siendo de 160.000 mrs. para posteriormente disminuir o aumentar según la situación económica o, incluso, dependiendo de las relaciones existentes en cada momento entre Ciudad y cabildo. Lo habitual fue que la Ciudad utilizara distintas facultades de sisa sobre determinados productos para obtener la cuantía de su ofrenda.

- El obispo: solía hacer dos ofrendas, una institucionalizada en concepto de limosna de la mitra o Mesa episcopal que podía pagarse incluso estando la sede vacante y que se realizaba el día de San Pedro, 29 de junio; y otra personalizada, esto es, por decisión del prelado concreto que ocupara la sede cuya cuantía varió considerablemente de unos obispos a otros. La Fábrica recibía por razón de la ofrenda institucional del obispo $40.000 \mathrm{mrs}$; no obstante, esta ofrenda no fue ni lo regular ni lo cuantiosa que cabía esperarse del máximo representante de la diócesis segoviana.

- El cabildo: el cabildo en cuanto institución con personalidad jurídica propia hacía su ofrenda, también el día de San Pedro como el obispo, que suponía alrededor de 5.500 reales. Junto con esta ofrenda aparece en los libros la realizada por La clerecía (clérigos seculares avecindados en la ciudad, excluido el clero capitular que contribuía separadamente) que desde el incendio de la torre de la catedral ocurrido en 1614, efectuaba su ofrenda en su aniversario: el 19 de septiembre.

- La Junta de Nobles Linajes y los Caballeros: la Junta contribuía en cuanto institución representativa de la élite de la nobleza urbana; los Caballeros en cuanto personas nobles, ya que no todos los caballeros o nobles de la ciudad habían logrado entrar en la Junta. Ambos estamentos realizaban su ofrenda el primer día del año con una cantidad que variaba entre 1.100 y 3.500 reales. 
- Gremios de oficios: cada uno de los oficios que había en la ciudad, agrupados en sus respectivos gremios, realizaban sus ofrendas normalmente en las celebraciones de sus respectivos patrones. Evidentemente, su importancia oscilaba en función de la implantación que tuviera en la ciudad la industria a la que representaban.

- Naciones: la enorme afluencia de emigrantes en la época más próspera de la ciudad hizo que algunos de ellos se agruparan en función de su origen y realizaran la ofrenda de forma independiente a los gremios respectivos. Dos, en concreto, fueron las naciones representadas en las ofrendas que recibió la Fábrica: vizcaínos y montañeses.

- Parroquias: algunas de ellas mantuvieron una ofrenda individualizada e independiente de los gremios afincados en ellas durante toda la construcción del nuevo templo catedralicio.

Comparando la aportación total de cada una de estas ofrendas, puede obtenerse un gráfico que resuma la participación final de cada estamento en este tipo de rentas que administró la Fábrica de la catedral de Segovia durante la edificación:

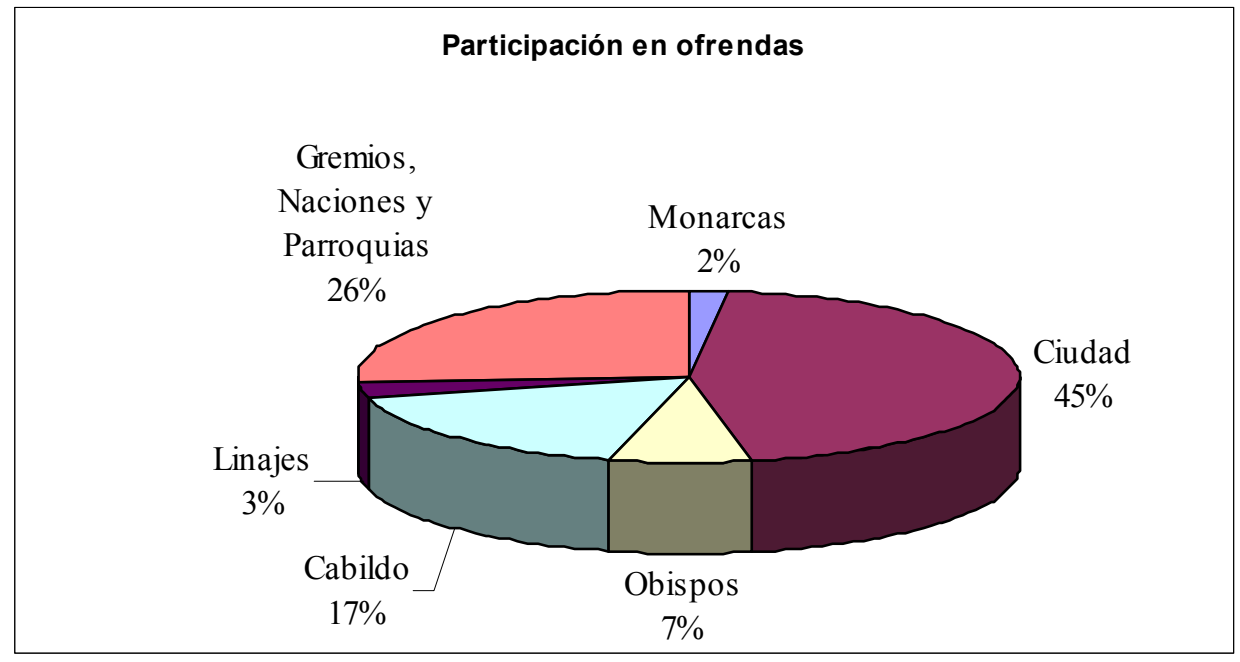


Analizando la información de este gráfico, parece quedar claro que la aportación a la edificación de la catedral de Segovia realizada por los Monarcas y los Linajes fue prácticamente insignificante, mientras que en el porcentaje final de la de los Obispos influye de manera importante la realizada, a título individual, por Antonio Idiáquez Manrique (6.000 ducados para el arreglo del incendio de la torre), puesto que por sí sola supone el $25 \%$ del total de la misma; sin esta aportación el porcentaje de participación final de los prelados hubiera sido, asimismo, muy pequeño. Más peso tuvieron las ofrendas que realizaron los miembros del Cabildo (donde influye la vinculación directa que tenían con el templo) y los Gremios que, en conjunto, se equiparan con la principal que fue la efectuada por el Ayuntamiento, aunque esta última también saliera en última instancia del bolsillo del ciudadano a través de la sisa que esta institución aplicaba sobre el consumo de ciertos productos. Por otra parte, también se puede evaluar qué tipo de ofrendas, las de tipo religioso o las de tipo laico, tuvieron un mayor peso en la financiación de la nueva catedral de Segovia. Parece claro que fueron las ofrendas laicas pues, en conjunto, supusieron casi el $75 \%$ de todas las ofrendas, es decir, aportaron tres veces más que la suma de las ofrendas de las instituciones religiosas. A la luz de todos estos datos, se puede concluir que fueron los vecinos de la ciudad los que más activamente participaron en estas rentas que supusieron la base financiera sobre la que se edificó la catedral de Segovia.

\section{BIBLIOGRAFÍA}

AldeA VAquero, Q. (1973) Diccionario de Historia Eclesiástica de España, 5 vols. Madrid: Consejo Superior de Investigaciones Científicas.

ASENJo González, M. (1986) Segovia, la Ciudad y su Tierra a fines del Medievo. Segovia: Diputación Provincial de Segovia.

COLMENARES, D. de (1965) Historia de la insigne ciudad de Segovia y compendio de historias de Castilla, Segovia, 1637, Edición crítica de la Academia de Historia y Arte de San Quirce, Segovia, 2 vols.

CORTÓN DE LAS HERAS, M.T. (1997) La construcción de la catedral de Segovia (1525-1607). Segovia: Caja de Ahorros y Monte de Piedad.

DIAZ-MIGUEL, M.D. (1968) "Relación de Juan Rodríguez, fabriquero mayor de la catedral de Segovia", Estudios Segovianos, XX, pp. 215-229. 
García y GarcíA-EstéVez, Á. (1998) "Episcopologio de la Diócesis de Segovia. Noticias de los Obispos de Segovia desde sus orígenes hasta nuestros días", Estudios Segovianos, XL, pp. 177-346.

GARCíA SANZ, Á. (1985) "Cómo se financió la construcción de la catedral de Segovia", Estudios Segovianos, XXIX, pp. 181-230.

GonZÁlez Herrero, M. (1971) "La antigua provincia de Segovia (Notas de Geografía histórica segoviana)", Estudios Segovianos, XXI, pp. 353-385.

REAL ACADEMIA ESPAÑOLA (1992) Diccionario de la lengua española, Vigésima primera edición, 2 vols. Madrid: Espasa.

Teruel GRegorio de TeJADA, M. (1993) Vocabulario básico de la historia de la Iglesia. Barcelona: Crítica. 